\title{
Epidemiologic profile of hepatitis C virus infection and genotype distribution in Burkina Faso: a systematic review with meta-analysis
}

Serge Ouoba ${ }^{1,2}$, Jean Claude Romaric Pingdwinde Ouedraogo ${ }^{3}$, Moussa Lingani ${ }^{2}$, Bunthen $E^{1,4}$, Md Razeen Ashraf Hussain ${ }^{1}$, Ko Ko' ${ }^{1}$ Shintaro Nagashima' ', Aya Sugiyama' , Tomoyuki Akita' , Halidou Tinto ${ }^{2}$ and Junko Tanaka ${ }^{1 *}$

\begin{abstract}
Background: Detailed characteristics of Hepatitis C virus (HCV) infection in Burkina Faso are scarce. The main aim of this study was to assess HCV seroprevalence in various settings and populations at risk in Burkina Faso between 1990 and 2020. Secondary objectives included the prevalence of HCV Ribonucleic acid (RNA) and the distribution of HCV genotypes.

Methods: A systematic database search, supplemented by a manual search, was conducted in PubMed, Web of Science, Scopus, and African Index Medicus. Studies reporting HCV seroprevalence data in low and high-risk populations in Burkina Faso were included, and a random-effects meta-analysis was applied. Risk of bias was assessed using the Joanna Briggs institute checklist.

Results: Low-risk populations were examined in 31 studies involving a total of 168,151 subjects, of whom 8330 were positive for HCV antibodies. Six studies included a total of 1484 high-risk persons, and 96 had antibodies to HCV. The pooled seroprevalence in low-risk populations was 3.72\% (95\% Cl: 3.20-4.28) and 4.75\% (95\% Cl: 1.79-8.94) in highrisk groups. A non-significant decreasing trend was observed over the study period. Seven studies tested HCV RNA in a total of 4759 individuals at low risk for HCV infection, and 81 were positive. The meta-analysis of HCV RNA yielded a pooled prevalence of $1.65 \%$ (95\% Cl: $0.74-2.89 \%$ ) in low-risk populations, which is assumed to be indicative of HCV prevalence in the general population of Burkina Faso and suggests that about 301,174 people are active HCV carriers in the country. Genotypes 2 and 1 were the most frequent, with $60.3 \%$ and $25.0 \%$, respectively.

Conclusions: HCV seroprevalence is intermediate in Burkina Faso and indicates the need to implement effective control strategies. There is a paucity of data at the national level and for rural and high-risk populations. General population screening and linkage to care are recommended, with special attention to rural and high-risk populations.
\end{abstract}

Keywords: Hepatitis C, Seroprevalence, Prevalence, Genotype, Systematic review, Burkina Faso

*Correspondence: jun-tanaka@hiroshima-u.ac.jp

${ }^{1}$ Department of Epidemiology, Infectious Disease Control and Prevention, Graduate School of Biomedical and Health Sciences, Hiroshima University, 1-2-3, Kasumi, Minami-ku, Hiroshima 734-8551, Japan

Full list of author information is available at the end of the article

\section{Background}

Hepatitis $\mathrm{C}$ virus (HCV) infection is a bloodborne disease which is globally distributed that mainly affects developing countries. In 2019, an estimated 58 million chronic cases were reported in the world [1], $75 \%$ of which occurred in low- and middle-income countries (LMIC) [2]. Worldwide, new HCV infections occur in 
high-risk populations, including people who inject drugs (PWID) and men who have sex with men (MSM) [3]. In sub-Saharan Africa, $\mathrm{HCV}$ is mainly transmitted via unsafe medical practices and contaminated blood transfusion [4]. Other transmission routes include needlestick injury in healthcare workers, mother-to-child transmission (MTCT), and social practices such as piercing and tattooing [3].

$\mathrm{HCV}$ infections are usually asymptomatic and silently progress over time. Up to $25 \%$ of new infections spontaneously resolve [5], and the remaining evolve to chronicity with complications such as liver cirrhosis and hepatocellular carcinoma (HCC) [3]. Since no vaccine is available to prevent $\mathrm{HCV}$ infection and its chronic consequences, screening and treatment of cases using effective direct-acting antivirals (DAA) are required [6]. $\mathrm{HCV}$ antibody (anti-HCV) assays are typically positive within 4-10 weeks after the initial infection, persist lifelong, and indicate a current or past exposure to the virus [7]. Thus, the WHO requires a confirmatory test by detecting $\mathrm{HCV}$ ribonucleic acid (HCV RNA) or core antigen ( $\mathrm{HCV} \mathrm{CAg}$ ) [8].

In Burkina Faso, a West African country, the epidemiologic patterns of $\mathrm{HCV}$ infection are poorly documented. The only nationwide study conducted in 2010 reported a seroprevalence of $3.6 \%$ (95\% CI: 3.3-3.8) in the general population [9]. In addition, various seroprevalence data classify the country among those of intermediate or high seroprevalence (seroprevalence $\geq 2 \%$ or $\geq 5 \%$, respectively) [10-12]. However, detailed characteristics of the infection in specific populations and geographic areas are scarce, representing a limitation for implementing effective control strategies. Thus, this study aimed to provide detailed knowledge on the epidemiologic profile of $\mathrm{HCV}$ infection in Burkina Faso by synthesizing data on $\mathrm{HCV}$ seroprevalence in various settings and populations at-risk in Burkina Faso. Secondary objectives included the prevalence of HCV RNA and the distribution of genotypes in the country.

\section{Methods}

\section{Study design and guidelines}

We conducted a systematic review with meta-analysis following the Joanna Briggs Institute guidelines for systematic reviews of studies reporting prevalence data [13]. This manuscript is reported according to the Meta-analysis Of Observational Studies in Epidemiology (MOOSE) recommendations [14].

\section{Study setting}

Burkina Faso is a landlocked country in West Africa with an overall population of 20,487,979 people in 2019 [15]. The country is divided into 13 regions, with the central region accounting for $14.8 \%$ of the total population. About one in four inhabitants live in rural areas. This developing country is characterized by the persistence of tropical infections and the epidemiological transition to non-transmissible diseases.

\section{Data source and study selection}

We searched the following databases to identify records published between 1990 and 2020: PubMed, Web of Science, Scopus, and African Index Medicus. A complete list of the search queries is shown in Additional file 1: Table S1. Besides, a manual search was conducted on African Journals Online (AJOL), Google Scholar, the reference lists of eligible reports, and the electronic library of the University Joseph Ki-Zerbo (www.biblio-ujkz. com), the largest university in the country. The last search was conducted on July 1, 2020, and reports in English or French were eligible. After removing duplicates using the EndNote reference manager, two independent investigators (SO and JCRPO) screened the records based on their titles and abstracts. Those deemed relevant were retained for full-text review. Any report (journal article, conference abstract, government report) of HCV antibody testing among people living in Burkina Faso was considered for inclusion. Reports that did not mention sample size and number of cases (or prevalence) were excluded. Disagreements between the two investigators were solved by discussion. When there was no consensus, the final decision was made by a third investigator (ML).

\section{Data extraction}

A pre-piloted standardized electronic data extraction form was used to extract relevant data: authors names, year of publication, study setting, study design, sampling method, study period, characteristics of study subjects (age, sex, location, co-morbidities), sample size, number of participants positive for anti-HCV, and type of biological assay. We also extracted HCV RNA and genotyping data when available. In this paper, a "report" refers to any document mentioning HCV seroprevalence data, and a "study" relates to the measurement of anti-HCV antibodies in a given population or setting (rural/urban). Therefore, one report may describe multiple studies, and in this case, we extracted data for each study separately. When data were suspected to originate from the same source, only one publication was included.

\section{Quality appraisal}

Joanna Briggs Institute checklist for prevalence studies was used to appraise the methodological quality of the studies [13]. Before independently using the tool, the reviewers agreed on the minimum acceptable information for each item. Sample size was considered adequate 
when more than 411 subjects were included. This was based on an assumed seroprevalence of $3.6 \%$ [9], a precision of $1.8 \%$, and a confidence level of $95 \%$. For the sampling procedure, only probabilistic sampling was considered representative of the target population. AntiHCV seroprevalence data was considered valid when the diagnostic was based on biological testing.

\section{Data synthesis and analysis}

We categorized the study populations into two groups based on the risk of HCV transmission. The low-risk group included the general population, blood donors, pregnant women, and children. People living with Human Immunodeficiency Virus (HIV), sex workers, MSM, and healthcare workers represented the high-risk group.

A meta-analysis of proportion was performed using the 'meta' and 'metafor' packages in the statistical program R. Data were transformed using the Freeman-Tukey double arcsine method to account for small proportions. The Dersimonian and Laird method, based on the randomeffects model, was used to perform the meta-analysis and summarize data in a forest plot. Confidence-interval (CI) for individual studies proportions were calculated using the Clopper-Pearson method. Heterogeneity was assessed based on the Cochran Q test and quantified by the $\mathrm{I}^{2}$ index. Heterogeneity was considered significant when the $\mathrm{p}$-value of the Cochran $\mathrm{Q}$ test was less than 0.05 . The level of heterogeneity was rated as high, medium, or low when the $\mathrm{I}^{2}$ index was $75 \%, 50 \%$, and
25\%, respectively [16]. Publication bias was evaluated graphically by a funnel plot of the transformed proportion against the sample size [17]. We used the Egger test to assess the symmetry of the plot $(\mathrm{p}<0.1)$.

\section{Results}

\section{Search results}

A total of 377 records were identified from the database search. After duplicates exclusion and titles and abstracts screening, 32 reports were selected for full-text review. Of these, 25 met the inclusion criteria, and six reports were further included, resulting in 31 reports. Finally, the qualitative review and the meta-analysis included 37 studies covering a population of 169,635 , as some reports provided data on multiple populations or settings. The selection process is summarized in Fig. 1.

\section{Study characteristics}

The details about the characteristics of each study are reported in Table 1. Studies were conducted between 1994 and 2018. The central region was the most represented (22/37 studies), and seven studies addressed the rural area. The cross-sectional design (33/37) was the main method used, with only eight studies (21.62\%) using a probabilistic sampling. Sample size was considered adequate ( $>411)$ in $46.0 \%$ of the studies, and the presence of anti-HCV antibodies was ascertained by biological assays in 34 studies (92.0\%) (Additional file 1: Table S2). Enzyme immunoassays (ELISA, CLEIA) were

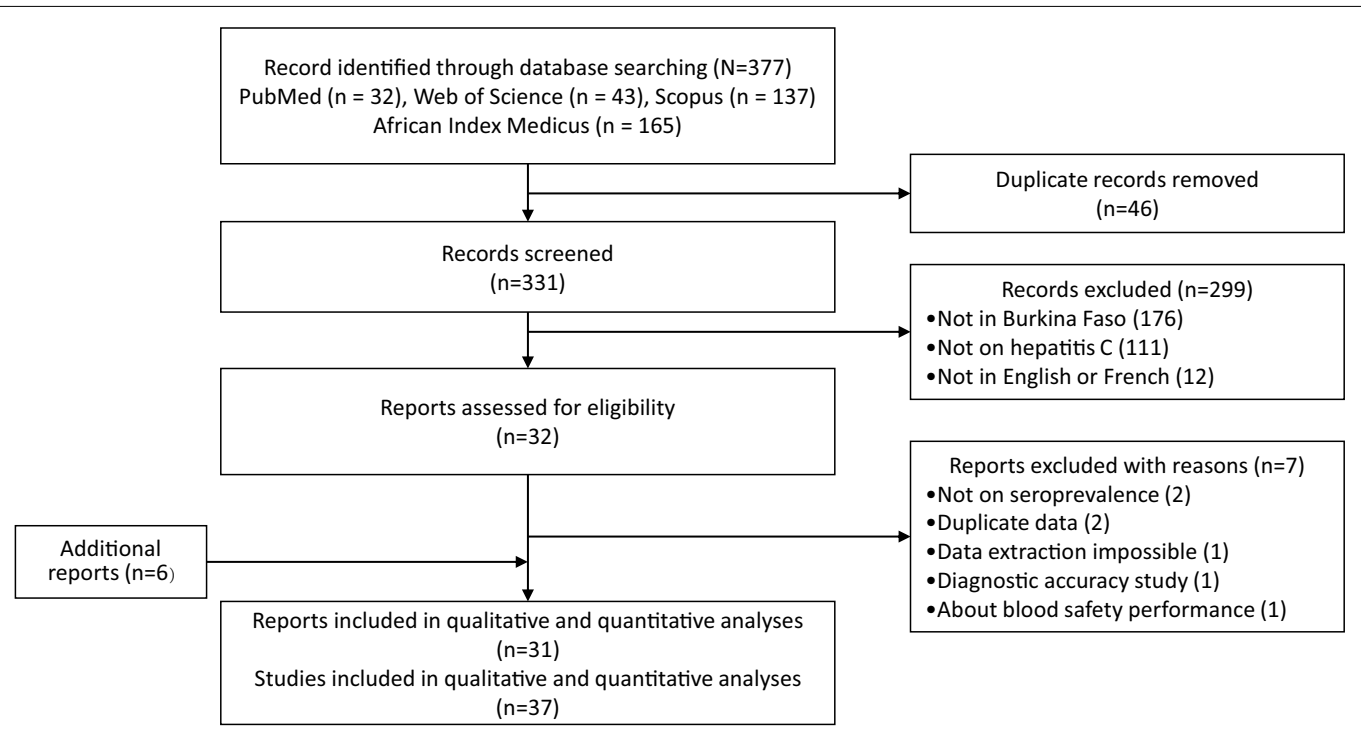

Fig. 1 Flowchart of records identification and study selection. A "report" refers to any document mentioning HCV seroprevalence data, and a "study" relates to the measurement of anti-HCV antibodies in a specific population or setting. Of the 31 reports that met the review criteria, four reported seroprevalence data on separate study subjects or settings (as shown in Table 1), and each seroprevalence data was extracted as an individual study. Therefore, 31 reports met the criteria for this review, and 37 prevalence data, referred to as "studies", were extracted 


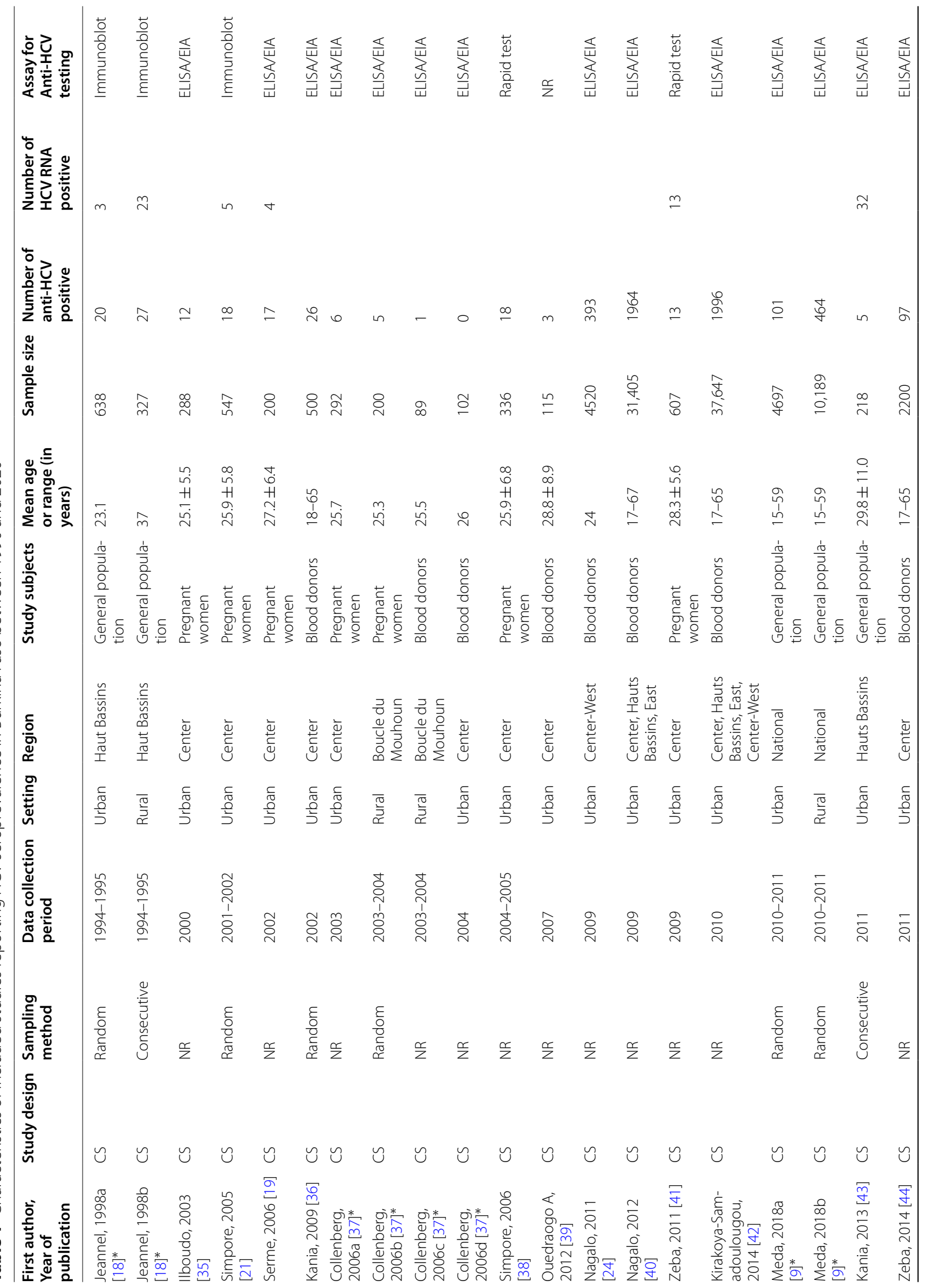




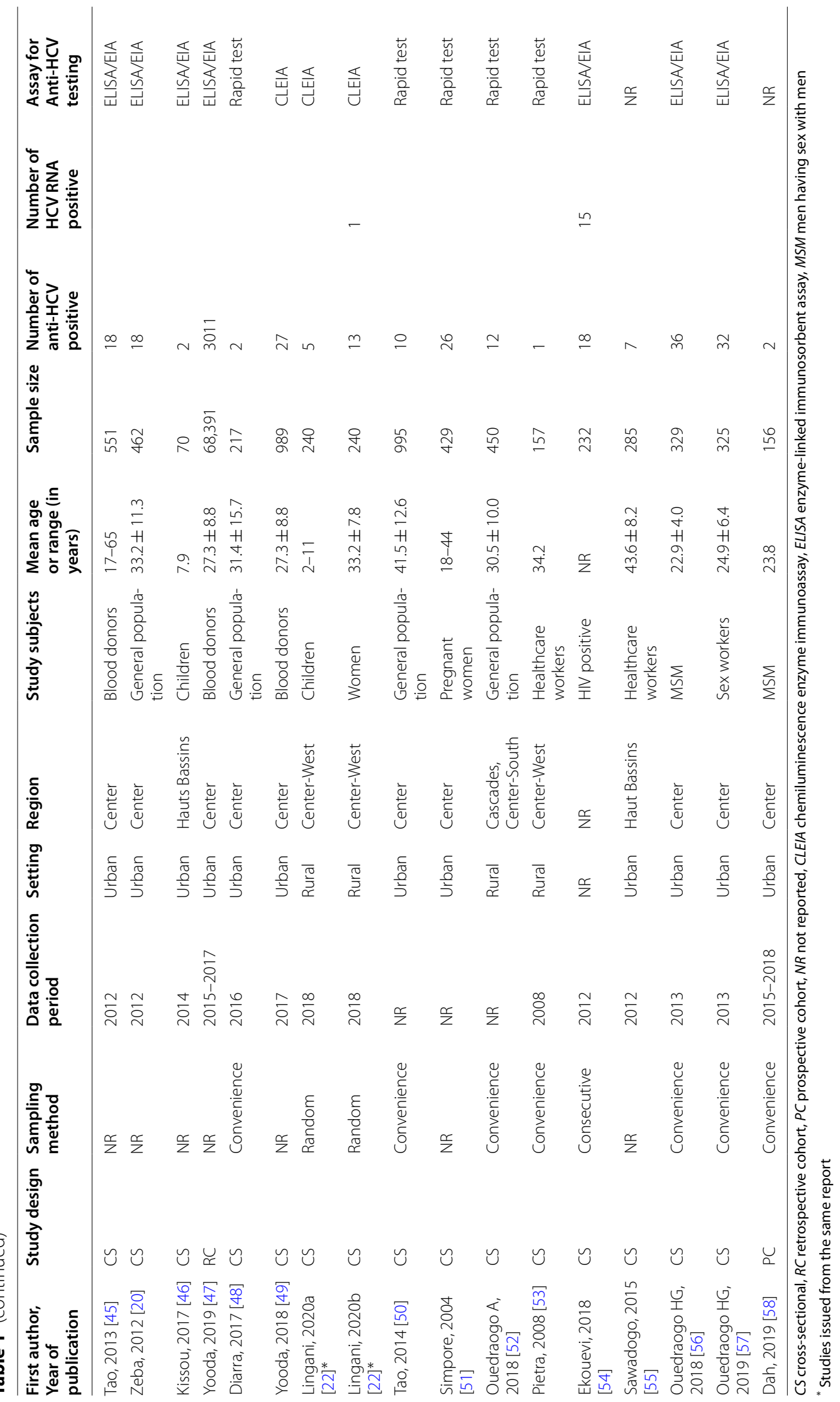


the most used (24/34 studies), followed by rapid tests (7/34) and immunoblotting (3/34).

\section{Seroprevalence in the low-risk group}

Low-risk populations were addressed in 31 studies and involved a total of 168,151 subjects, of whom 8330 were positive for HCV antibodies. Ten studies focused on the general population, eleven on blood donors, eight on pregnant women, and two on children. The seroprevalence ranged between 0 and $8.69 \%$, and the pooled seroprevalence was $3.72 \%$ (95\% CI: $3.20-4.28$ ). However, significant heterogeneity was found in this group $\left(\mathrm{I}^{2}=94.42 \%, \mathrm{p}<0.001\right)$ (Fig. 2$)$.

\section{Seroprevalence in the high-risk group}

Subjects in the high-risk group were investigated in six studies: two on healthcare professionals, two on men having sex with men (MSM), one on people living with $\mathrm{HIV}$, and one on sex workers. A total of 1,484 high-risk persons were studied, and 96 had antibodies to HCV. Seroprevalence varied from $1.28 \%$ to $10.94 \%$ (Fig. 2), and the combined seroprevalence was $4.75 \%$ (95\% CI: 1.79 $8.94)$. Heterogeneity was also significant in this group $\left(\mathrm{I}^{2}=90.26 \%, \mathrm{p}<0.001\right)$.

\section{Seroprevalence by study subjects}

Among populations with a low risk of infection, blood donors had the highest seroprevalence $(4.51 \%, 95 \% \mathrm{CI}$ : $\left.3.73-5.35, \mathrm{I}^{2}=96.51 \%, \mathrm{p}<0.001\right)$, followed by pregnant women (3.95\%, 95\% CI: $\left.2.67-5.46, \mathrm{I}^{2}=71.86 \%, \mathrm{p}<0.001\right)$.

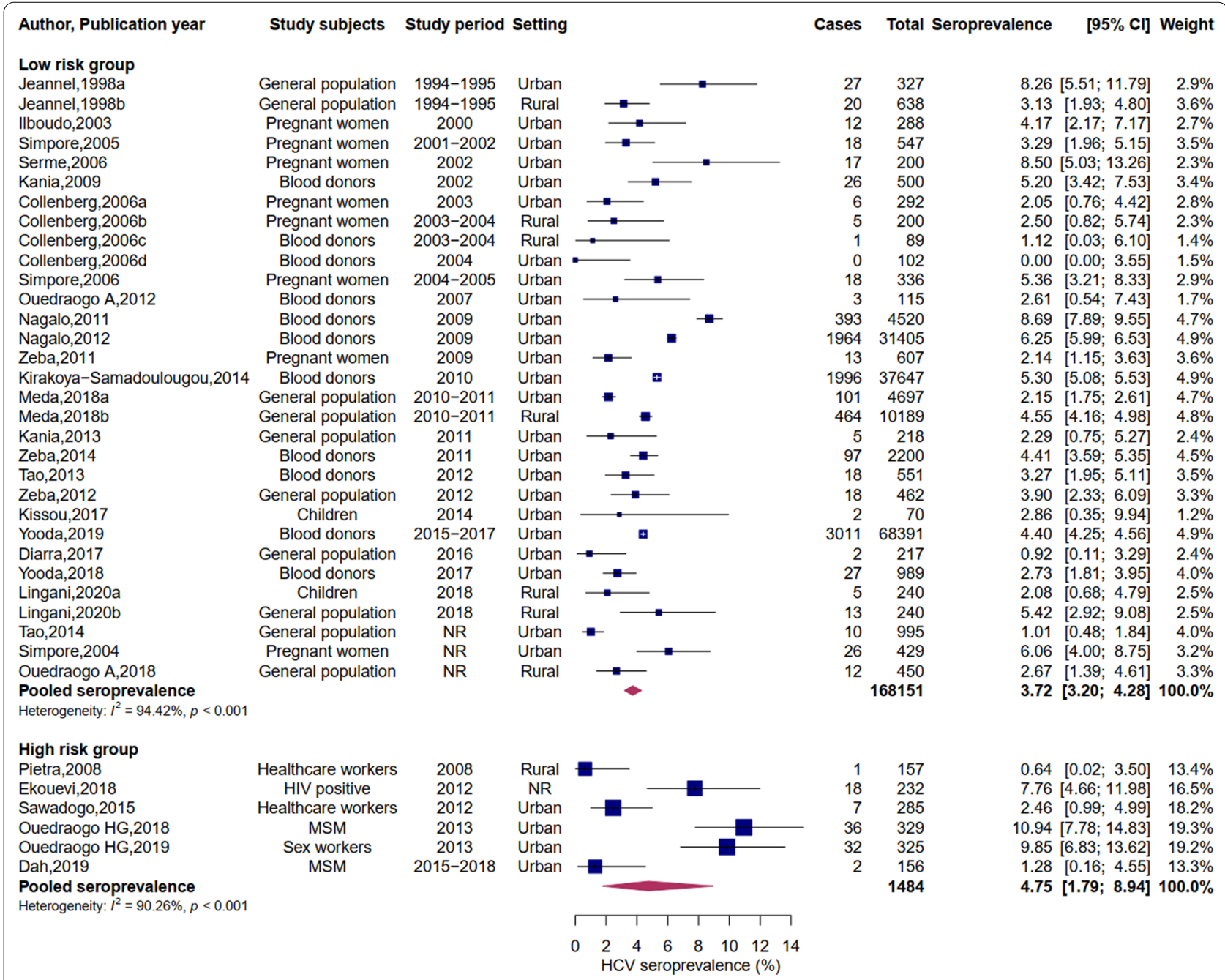

Fig. 2 Meta-analysis of HCV seroprevalence in Burkina Faso by risk group. Pooled seroprevalence based on random-effects model. Low-risk group includes the general population, blood donors, pregnant women, and children. High-risk group is constituted of people living with Human Immunodeficiency Virus (HIV), sex workers, men having sex with men (MSM) and healthcare workers 
The seroprevalence in the general population was $3.11 \%$ (95\% CI: $2.05-4.38, \mathrm{I}^{2}=92.14 \%, \mathrm{p}<0.001$ ), and $2.11 \%$ (95\% CI: $\left.0.68-4.16, \mathrm{I}^{2}=0 \%, \mathrm{p}=0.59\right)$ in children. $\mathrm{HCV}$ seroprevalence was highest among sex workers $(9.85 \%$, 95\% CI: 6.82-13.34) and HIV patients (7.76\%, 95\% CI: 4.63-11.59). Healthcare workers had the lowest seroprevalence $(1.57 \%, 95 \% \mathrm{CI}: 0.28-3.68, \mathrm{p}=0.18)$. The summary of the seroprevalence by study subjects is shown in Table 2.

\section{Seroprevalence by study setting}

The analysis of the seroprevalence by study setting was performed considering only low-risk groups (Table 2). Seven studies were conducted in rural areas and covered a population of 12,046 people. The pooled seroprevalence was $3.27 \%$ (95\% CI: 2.35-4.33, $\left.\mathrm{I}^{2}=59.24 \%, \mathrm{p}=0.02\right)$. Urban populations were addressed in 24 studies and yielded a combined seroprevalence of $4.02 \%$ (95\% CI: $\left.3.40-4.68, \mathrm{I}^{2}=95.44 \%, \mathrm{p}<0.001\right)$.

\section{Seroprevalence by the decade of data collection}

Only low-risk populations were considered for the analysis of HCV seroprevalence by the period of data collection. Two studies were conducted between 1990 and 2000 , resulting in a pooled seroprevalence of $5.33 \%(95 \%$ CI: $\left.1.42-11.45, \mathrm{I}^{2}=91.06 \%, \mathrm{p}<0.001\right)$. The seroprevalence decreased to $3.95 \%$ (95\% CI: $2.85-5.21, \mathrm{I}^{2}=90.37 \%$, $\mathrm{p}<0.001,13$ studies) during 2000-2010 and to $3.78 \%$ (95\% CI: 3.19-4.41, I ${ }^{2}=92.71 \%, \mathrm{p}<0.001,13$ studies) between 2010 and 2020 (Table 2). However, this decrease was not significant ( $\mathrm{p}$ for difference $=0.78$ ).

\section{HCV RNA prevalence}

Eight studies assessed the presence of HCV RNA, including two in rural settings and only one in the high-risk group. HCV RNA prevalence ranged from 0.47 to $7.03 \%$. The highest prevalence estimates were found in HIVpositive patients $(6.47 \%)$ and urban populations surveyed in 1994-1995 (7.03\%). The seven studies that tested HCV RNA in low-risk populations included a total of 4,759 individuals, of whom 81 were positive. The meta-analysis yielded a pooled HCV RNA prevalence of $1.65 \%$ (95\% CI: $\left.0.74-2.89, \mathrm{I}^{2}=85.04 \%, \mathrm{p}<0.001\right)$ in the low-risk group. Figure 3 shows the forest plot of HCV RNA prevalence.

\section{HCV genotypes}

The genotyping of the virus was performed in six studies [18-22], and genotype 2 was the most predominant (60.3\%), followed by genotype 1 (25.0\%) and genotype 3 (7.4\%). Mixed infections accounted for $5.9 \%$, and genotype 4 was found in only one subject (1.5\%) (Fig. 4).

\section{Publication bias}

No publication bias was observed through the graphical assessment of the funnel plot (Fig. 5) and the Egger test for funnel plot asymmetry ( $\mathrm{p}$-value $=0.23$ ).

Table 2 HCV seroprevalence in subgroups

\begin{tabular}{|c|c|c|c|c|c|c|}
\hline Categories & $\begin{array}{l}\text { Number of } \\
\text { studies }\end{array}$ & Total population & $\begin{array}{l}\text { Pooled } \\
\text { seroprevalence }\end{array}$ & $95 \% \mathrm{Cl}$ & $I^{2}$ index (\%) & $\begin{array}{l}\text { Cochran } \\
\text { Q test } \\
\text { p-value }\end{array}$ \\
\hline \multicolumn{7}{|l|}{ Study subjects } \\
\hline General population & 10 & 18,433 & 3.11 & $2.05-4.38$ & 92.14 & $<0.001$ \\
\hline Blood donors & 11 & 146,509 & 4.51 & $3.73-5.35$ & 96.51 & $<0.001$ \\
\hline Pregnant women & 8 & 2899 & 3.95 & $2.67-5.46$ & 71.86 & $<0.001$ \\
\hline Children & 2 & 310 & 2.11 & $0.68-4.16$ & 0 & 0.59 \\
\hline Healthcare workers & 2 & 442 & 1.57 & $0.28-3.68$ & 44.09 & 0.18 \\
\hline MSM & 2 & 485 & 5.19 & $0.00-18.25$ & 94.81 & $<0.001$ \\
\hline Sex workers & 1 & 325 & 9.85 & $6.82-13.34$ & NA & NA \\
\hline HIV patients & 1 & 232 & 7.76 & $4.63-11.59$ & NA & NA \\
\hline \multicolumn{7}{|l|}{ Study setting* } \\
\hline Urban & 25 & 156,420 & 4.02 & $3.40-4.68$ & 95.44 & $<0.001$ \\
\hline Rural & 7 & 12,046 & 3.27 & $2.35-4.33$ & 59.24 & 0.02 \\
\hline \multicolumn{7}{|c|}{ Decade of data collection* } \\
\hline 1990-2000 & 2 & 965 & 5.33 & $1.42-11.45$ & 91.06 & $<0.001$ \\
\hline $2000-2010$ & 13 & 39,201 & 3.95 & $2.85-5.21$ & 90.37 & $<0.001$ \\
\hline 2010-2020 & 12 & 126,111 & 3.77 & $3.25-4.32$ & 92.71 & $<0.001$ \\
\hline
\end{tabular}

*Analyses performed considering only low-risk populations (general population, blood donors, pregnant women, children) 
Author, Publication year Study subjects Study period Setting

Low risk group Jeannel, 1998b Jeannel, 1998a Simpore, 2005 Serme, 2006

Zeba, 2011

Zeba, 2014

Lingani,2020b

Pooled prevalence

Heterogeneity: $I^{2}=85.04 \%, p<0.00$

High risk group

Ekouevi,2018

Pooled prevalence

Heterogeneity: not applicable

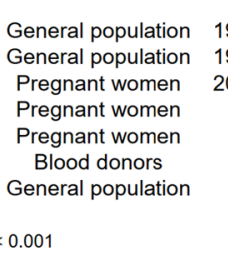

1994-1995

Urban $2001-2002$
2009 2009

2011

2018

Urban

Urban

Urban

Rural

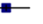

$\rightarrow$
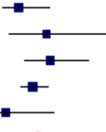

\section{Cases Total Prevalence $[95 \% \mathrm{Cl}]$ Weight}

$\begin{array}{rrrrrr}3 & 638 & 0.47 & {[0.10 ; 1.37]} & 15.1 \% \\ 23 & 327 & & 7.03 & {[4.51 ; 10.37]} & 13.7 \% \\ 5 & 547 & & 0.91 & {[0.30 ; 2.12]} & 14.8 \% \\ 4 & 200 & 2.00 & {[0.55 ; 5.04]} & 12.2 \% \\ 13 & 607 & 2.14 & {[1.15 ; 3.63]} & 15.0 \% \\ 32 & 2200 & 1.45 & {[1.00 ; 2.05]} & 16.3 \% \\ 1 & 240 & 0.42 & {[0.01 ; 2.30]} & 12.8 \% \\ \mathbf{4 7 5 9} & & \mathbf{1 . 6 5} & {[\mathbf{0 . 7 4} ; \mathbf{2 . 8 9}]} & \mathbf{1 0 0 . 0 \%}\end{array}$

$\begin{array}{lll}15 & 232 & 6.47[3.66 ; 10.44] 100.0 \%\end{array}$ $2326.47[3.62 ; 10.03] 100.0 \%$

Fig. 3 Meta-analysis of HCV RNA prevalence in Burkina Faso by risk group. Pooled prevalence based on random-effects model. Low-risk group includes the general population, blood donors, and pregnant women. Only one study evaluated HCV RNA in high-risk groups (people living with HIV)

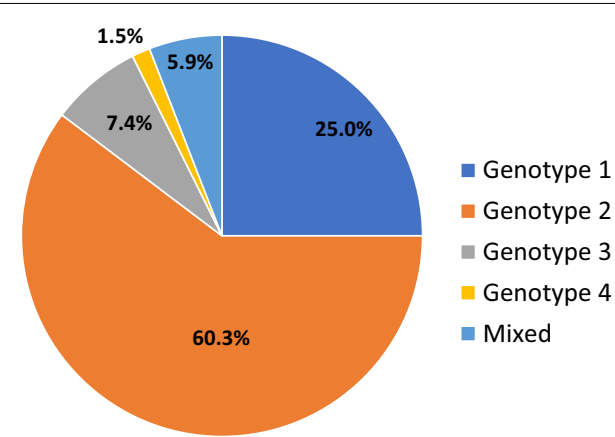

Fig. 4 Distribution of HCV genotypes in Burkina Faso. Mixed infections consisted of genotypes $2 / 3$ and $2 / 4$

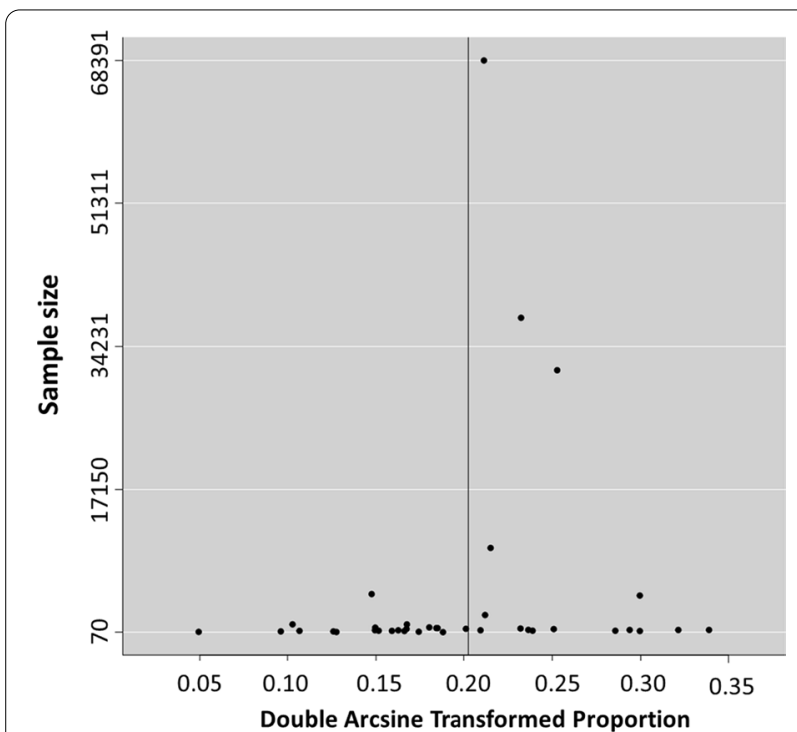

Fig. 5 Funnel plot of HCV seroprevalence meta-analysis. Double arcsine transformed proportion of individual studies is plotted against the sample size. The symmetrical distribution of studies in the funnel plot suggests an absence of publication bias

\section{Discussion}

We evaluated the seroprevalence of HCV infection in Burkina Faso between 1990 and 2020 in several settings and populations. The reported seroprevalence in low-risk groups was $3.72 \%$ (95\% CI: $3.20-4.28)$ and may reflect that of the general population, classifying the country among those with intermediate seroprevalence [8]. Previous analyses reported a seroprevalence between 4.9 and $6.1 \%$ in Burkina Faso, ranking the country among those with the highest seroprevalence in West Africa [10, 12]. However, these reports included high-risk populations in their estimations. In addition, as HCV seroprevalence decreased over time, the inclusion of more recent studies in our review may explain our lower rate. The rate reported in this review is similar to that of the only nationwide survey conducted in 2010, which found a weighted seroprevalence of 3.6\% (95\% CI: 3.3-3.8) in the general population [9].

Although non-significant, a decreasing trend was observed over the past three decades and can be attributed to several factors, including the improvement of transfusion and injection safety. Since 2000, blood transfusion in Burkina Faso is managed by the national center for blood transfusion (CNTS), which has the capacity for infection screening. However, in 2009, its production capacity covered only half of the needs, with the remaining directly collected in the health facilities not supplied by the CNTS. A survey of 42 of these health centers showed that $14.3 \%$ were not routinely performing $\mathrm{HCV}$ testing [23]. In addition, a residual risk of $\mathrm{HCV}$ transmission persists, estimated at one in 213 donations, as blood screening for $\mathrm{HCV}$ is only based on the detection of anti-HCV antibodies [24, 25]. Therefore, nationwide coverage of the blood supply by the CNTS and nucleic acid testing for $\mathrm{HCV}$ is 
recommended to reduce the risk of transfusion-transmitted hepatitis $C$.

Improved injection safety is the other factor that could explain the downward trend of infection rates. Indeed, in 1996 , it was estimated that $11 \%$ of rural and $80 \%$ of urban health centers were using new and sterile syringes and needles for injections [26]. In 2000, a survey of 52 nationally representative health facilities found that this proportion increased to $96 \%$, and no shortage of syringes or needles was reported in those health centers [27].

The pooled seroprevalence of HCV infection among pregnant women indicates a risk for MTCT, estimated at $4.2-7.8 \%$ among viremic women [28]. Nevertheless, the WHO does not recommend routine testing of pregnant women for $\mathrm{HCV}$ infection, as currently there is no treatment to prevent MTCT, and DAAs are not indicated during pregnancy [2]. Therefore, adequate detection and treatment of childbearing age women during the preconception period could be recommended.

Rural communities were understudied, although they accounted for $73.7 \%$ of the latest national population census [15]. Therefore, the reported seroprevalence may underestimate the magnitude of the actual situation in rural settings. It is thus essential to assess the burden of HCV infection on rural populations, as limited care access, low literacy, and low socioeconomic status are known factors of HCV infection [4, 29].

Few studies were conducted among key populations for $\mathrm{HCV}$ infection. Interestingly, two studies included MSM and one involved sex workers, two hard-to-reach groups. However, no study was conducted among PWID. Evidence exists about injecting drug usage in Burkina Faso, but no data are available on PWID numbers [30]. Monitoring the extent of injecting drug use and HCV transmission among PWID and other key populations (e.g., MSM and sex workers) should be implemented.

The pooled HCV RNA prevalence among low-risk populations was $1.65 \%$ (95\% CI: $0.74-2.89 \%$ ) and may be indicative of the prevalence in the general population. By applying this rate to the total population of the country in 2019 [15], approximately 301,174 people are estimated to be active HCV carriers in Burkina Faso. The Polaris observatory estimated the total number of active carriers in Burkina Faso at 247,000 in 2015, corresponding to a viremic prevalence of $1.3 \%$ (95\% CI: $1.0-1.4 \%$ ), and higher than the global prevalence of $1 \%$ [31]. As HCV infection can be treated with highly effective DAAs, public effort should be undertaken to identify active carriers and link them to care.

Only six studies evaluated HCV genotype distribution, and genotypes 2 and 1 were the most prevalent, as reported by previous publications [4, 12, 32]. Since the advent of pangenotypic DAAs, genotype determination is considered of little interest in deciding the adequate treatment for chronic $\operatorname{HCV}[2,6]$. However, recent reports of treatment failures with pangenotypic DAAs in patients of African descent infected with genotypes 1 and $4[33,34]$ are alarms for monitoring circulating genotypes and evaluating the effectiveness of $\mathrm{HCV}$ treatment.

Our study is limited by the small sample size in rural and high-risk populations and the diversity of anti-HCV antibody measurement methods. Also, as expected from a meta-analysis of prevalence data, significant heterogeneity was observed and could be attributed to the various populations and geographic areas [13]. These factors may have underestimated or overestimated the actual seroprevalence. Despite these limitations, our results are valuable in guiding public health response in a setting where data on HCV infection in specific populations and settings are scarce.

\section{Conclusions}

In conclusion, the seroprevalence of HCV infection is intermediate in Burkina Faso, with a decreasing trend over the past 30 years, due to improved blood transfusion and injection safety. There is a paucity of data at the national level and for rural and high-risk populations. The fight against hepatitis $\mathrm{C}$ infection requires highquality and nationally representative data to guide public health response. Although general population testing is recommended, special attention should be paid to rural and high-risk populations, with screening and linkage to care.

\section{Abbreviations \\ HCV: Hepatitis C virus; DAA: Direct-acting antivirus; LMIC: Low- and middle- income countries; RNA: Ribonucleic acid; PWID: Persons who inject drugs; MTCT: Mother-to-child transmission; HCC: Hepatocellular carcinoma; HIV: Human immunodeficiency virus; MSM: Men having sex with men; ELISA: Enzyme-linked immunosorbent assay; CLEIA: Chemiluminescence enzyme immunoassay; CNTS: National center for blood transfusion; Cl: Confidence Interval.}

\section{Supplementary Information}

The online version contains supplementary material available at https://doi. org/10.1186/s12879-021-06817-x.

Additional file 1: Table S1. (Database search). Table S2. (Quality appraisal of included studies using the Joanna Briggs Institute checklist for prevalence studies).

\section{Acknowledgements}

We would like to thank the personnel of the Department of Epidemiology, Infectious Disease Control, and Prevention, Graduate School of Biomedical and Health Sciences, Hiroshima University, for their valuable support.

\section{Authors' contributions}

SO and JT conceptualized the study. SO, JCRPO and ML contributed to developing the study design and data acquisition. SO, TA, and JT analyzed and interpreted the data. SO, JCRPO, ML drafted the manuscript. EB, MRAH, AS, TA, 
SN, KK, HT, and JT contributed to the intellectual content of the manuscript. All authors read and approved the final manuscript.

\section{Funding}

This research did not receive any specific grant from funding agencies in the public, commercial, or not-for-profit sectors. OS received a Ph.D. scholarship from Japan's Ministry of Education, Culture, Sports, Science, and Technology (MEXT).

\section{Availability of data and materials}

The dataset used and analyzed in this study is available from the corresponding author on reasonable request.

\section{Declarations}

\section{Ethical approval and consent to participate}

Not applicable.

\section{Consent for publication}

Not applicable.

\section{Competing interests}

The authors declare no conflict of interest.

\section{Author details}

'Department of Epidemiology, Infectious Disease Control and Prevention, Graduate School of Biomedical and Health Sciences, Hiroshima University, 1-2-3, Kasumi, Minami-ku, Hiroshima 734-8551, Japan. ${ }^{2}$ Unité de Recherche Clinique de Nanoro (URCN), Institut de Recherche en Science de la Santé (IRSS), Nanoro, Burkina Faso. ${ }^{3}$ Département de Médecine et Pharmacopée Traditionnelles, Pharmacie, Institut de Recherche en Sciences de la Santé (IRSS), Ouagadougou, Burkina Faso. ${ }^{4}$ Payment Certification Agency (PCA), Ministry of Health, Phnom Penh, Cambodia.

Received: 8 July 2021 Accepted: 25 October 2021

Published online: 01 November 2021

\section{References}

1. World Health Organization. Global progress report on HIV, viral hepatitis and sexually transmitted infections, 2021. Accountability for the global health sector strategies 2016-2021: actions for impact. 2021.

2. World Health Organization. Accelerating access to hepatitis $C$ diagnostics and treatment Overcoming barriers in low- and middle-income countries Global progress report 2020. 2021. https://www.who.int/publications/i/ item/9789240019003.

3. Spearman CW, Dusheiko GM, Hellard M, Sonderup M. Hepatitis C. Lancet. 2019;394:1451-66.

4. Sonderup MW, Afihene M, Ally R, Apica B, Awuku Y, Cunha L, et al. Hepatitis $C$ in sub-Saharan Africa: the current status and recommendations for achieving elimination by 2030. Lancet Gastroenterol Hepatol. 2017;2(12):910-9. https://doi.org/10.1016/S2468-1253(17)30249-2.

5. Micallef JM, Kaldor JM, Dore GJ. Spontaneous viral clearance following acute hepatitis C infection: a systematic review of longitudinal studies. J Viral Hepatitis. 2006;13:34-41. https://doi.org/10.1111/j.1365-2893.2005. 00651.x.

6. Zoratti MJ, Siddiqua A, Morassut RE, Zeraatkar D, Chou R, van Holten J, et al. Pangenotypic direct acting antivirals for the treatment of chronic hepatitis C virus infection: a systematic literature review and meta-analysis. EClinicalMedicine. 2020;18: 100237. https://doi.org/10.1016/j.eclinm. 2019.12.007.

7. Schillie S, Wester C, Osborne M, Wesolowski L, Ryerson AB. CDC recommendations for hepatitis C screening among adults-United States, 2020 MMWR Recomm Rep. 2020;69(2):1-17.

8. World Health Organisation. Guidelines on Hepatitis B and C Testing. 2017. http://apps.who.int/iris/bitstream/10665/254621/1/9789241549981-eng. pdf?ua=1\%0Ahttp://www.ncbi.nlm.nih.gov/pubmed/28742301\%0Ahtt p://www.ncbi.nlm.nih.gov/pubmed/28742301. Accessed 14 Oct 2020.
9. Meda N, Tuaillon E, Kania D, Tiendrebeogo A, Pisoni A, Zida S, et al. Hepatitis B and C virus seroprevalence, Burkina Faso: a cross-sectional study. Bull World Health Organ. 2018;96(11):750-9.

10. Riou J, Aït Ahmed M, Blake A, Vozlinsky S, Brichler S, Eholié S, et al. Hepatitis $C$ virus seroprevalence in adults in Africa: a systematic review and meta-analysis. J Viral Hepat. 2016;23(4):244-55.

11. Rao VB, Johari N, du Cros P, Messina J, Ford N, Cooke GS. Hepatitis C seroprevalence and HIV co-infection in sub-Saharan Africa: a systematic review and meta-analysis. Lancet Infect Dis. 2015;15(7):819-24.

12. Petruzziello A, Marigliano S, Loquercio G, Cozzolino A, Cacciapuoti C. Global epidemiology of hepatitis C virus infection: an up-date of the distribution and circulation of hepatitis C virus genotypes. World J Gastroenterol. 2016:22(34):7824-40.

13. Munn Z, Moola S, Lisy K, Riitano D, Tufanaru C. Methodological guidance for systematic reviews of observational epidemiological studies reporting prevalence and cumulative incidence data. Int J Evid Based Healthc. 2015;13(3):147-53.

14. Stroup DF, Berlin JA, Morton SC, Olkin I, Williamson GD, Rennie D, et al. Meta-analysis of observational studies in epidemiology: a proposal for reporting. J Am Med Assoc. 2000;283(15):2008-12.

15. Ministere de l'economie et des finances. Cinquieme recensement general de la population et de l'habitation du Burkina Faso, Resultats preliminaires. 2020.

16. Higgins JPT, Thompson SG, Deeks JJ, Altman DG. Measuring inconsistency in meta-analyses. BMJ. 2003;327(7414):557-60.

17. Hunter JP, Saratzis A, Sutton AJ, Boucher RH, Sayers RD, Bown MJ. In meta-analyses of proportion studies, funnel plots were found to be an inaccurate method of assessing publication bias. J Clin Epidemiol. 2014;67(8):897-903.

18. Jeannel D, Fretz C, Traore Y, Kohdjo N, Bigot A, Gamy EP, et al. Evidence for high genetic diversity and long-term endemicity of hepatitis $C$ virus genotypes 1 and 2 in West Africa. J Med Virol. 1998;55(2):92-7.

19. Serme AK, Ilboudo PD, Samandoulgou A, Simpore J, Bougouma A, Sombie AR. Portage du virus de l'hépatite $C$ chez les femmes enceintes et transmission mère-enfant à Ouagadou-gou, Burkina Faso. Bull Soc Pathol Exot. 2006;99(2):108-9.

20. Zeba M, Ouattara CAT, Karou SD, Bisseye C, Ouermi D, Djigma FW, et al. Prevalence of HBV and HCV markers among patients attending the saint camille medical centre in Ouagadougou. Pak J Biol Sci. 2012;15(10):484-9.

21. Simpore J, Ilboudo D, Samandoulougou A, Guardo P, Castronovo P, Musumeci S. HCV and HIV co-infection in pregnant women attending St. Camille Medical Centre in Ouagadougou (Burkina Faso). J Med Virol. 2005;75(2):209-12.

22. Lingani M, Akita T, Ouoba S, Nagashima S, Boua PR, Takahashi K, et al. The changing epidemiology of hepatitis B and C infections in Nanoro, rural Burkina Faso: a random sampling survey. BMC Infect Dis. 2020;20(1):1-14.

23. Nébié K, Ouattara S, Sanou M, Kientega Y, Dahourou H, Ky L, et al. Poor procedures and quality control among nonaffiliated blood centers in Burkina Faso: an argument for expanding the reach of the national blood transfusion center. Transfusion. 2011;51(7 PART 2):1613-8.

24. Nagalo MB, Sanou M, Bisseye C, Kaboré MI, Nebie YK, Kienou K, et al. Seroprevalence of human immunodeficiency virus, hepatitis B and $C$ viruses and syphilis among blood donors in Koudougou (Burkina Faso) in 2009. Blood Transfus. 2011;9(4):419-24.

25. Koura M, Hema A, A C, Ouattara Z, Bere-Some C, Somda K, et al. Incidence et risque résiduel de transmission des virus de l'hépatite $B$ et $C$ par transfusion sanguine à Bobo-Dioulasso (Burkina Faso): Étude de cohorte. Sci Tech. 2017;40(2):25-33.

26. Dicko M, Oni A-QQ, Ganivet $S$, Kone S, Pierre L, Jacquet B. Safety of immunization injections in Africa: not simply a problem of logistics. Bull World Health Organ. 2000;78(2):163-9.

27. Fitzner J, Aguilera JF, Yameogo A, Duclos P, Hutin YJF. Injection practices in Burkina Faso in 2000. Int J Qual Health Care. 2004;16(4):303-8.

28. Benova L, Mohamoud YA, Calvert C, Abu-Raddad LJ. Vertical transmission of hepatitis $C$ virus: systematic review and meta-analysis. Clin Infect Dis. 2014;59(6):765-73.

29. Spearman CW, Sonderup MW. Health disparities in liver disease in subSaharan Africa. Liver Int. 2015;35:2063-71.

30. Degenhardt L, Peacock A, Colledge S, Leung J, Grebely J, Vickerman P, et al. Global prevalence of injecting drug use and sociodemographic characteristics and prevalence of HIV, HBV, and HCV in people who 
inject drugs: a multistage systematic review. Lancet Glob Health. 2017;5(12):e1192-207.

31. Blach S, Zeuzem S, Manns M, Altraif I, Duberg AS, Muljono DH, et al. Global prevalence and genotype distribution of hepatitis $C$ virus infection in 2015: a modelling study. Lancet Gastroenterol Hepatol. 2017;2(3):161-76.

32. Mora N, Adams WH, Kliethermes S, Dugas L, Balasubramanian N, Sandhu J, et al. A synthesis of hepatitis C prevalence estimates in Sub-Saharan Africa: 2000-2013. BMC Infect Dis. 2016;16:283.

33. Pawlotsky JM. DAA failures in African patients with "unusual" HCV subtypes: Hey! Didn't you know there was another world? J Hepatol. 2019;71:1070-2.

34. Childs K, Davis C, Cannon M, Montague S, Filipe A, Tong L, et al. Suboptimal SVR rates in African patients with atypical genotype 1 subtypes: implications for global elimination of hepatitis C. J Hepatol. 2019;71(6):1099-105.

35. Illboudo D, Sawadogo A, Simpore J. Co-infection hépatite C et VIH chez les femmes enceintes à Ouagadougou (Burkina Faso). Med Maladies Infect. 2003;33:278-9.

36. Kania D, Sangaré L, Sakandé J, Koanda A, Nébié YK, Zerbo O, et al. A new strategy to improve the cost-effectiveness of human immunodeficiency virus, hepatitis B virus, hepatitis C virus, and syphilis testing of blood donations in sub-Saharan Africa: a pilot study in Burkina Faso. Transfusion. 2009:49(10):2237-40.

37. Collenberg E, Ouedraogo T, Ganamé J, Fickenscher H, Kynast-Wolf G, Becher $\mathrm{H}$, et al. Seroprevalence of six different viruses among pregnant women and blood donors in rural and urban Burkina Faso: a comparative analysis. J Med Virol. 2006;78(5):683-92. https://doi.org/10.1002/jmv. 20593.

38. Simpore J, Savadogo A, Illboudo D, Nadambega MC, Esposito M, Yara J, et al. Toxoplasma gondii, HCV, and HBV seroprevalence and co-infection among HIV-positive and-negative pregnant women in Burkina Faso. J Med Virol. 2006;78(6):730-3.

39. Ouedraogo A, Yaméogo J, Poda G, Kientega Y, Traore R. Prévalence des anticorps anti-cytomégalovirus chez les donneurs de sang de ouagadougou (Burkina Faso). Med Sante Trop. 2012;22(1):107-9.

40. Nagalo BM, Bisseye C, Sanou M, Kienou K, Nebié YK, Kiba A, et al. Seroprevalence and incidence of transfusion-transmitted infectious diseases among blood donors from regional blood transfusion centres in Burkina Faso, West Africa. Trop Med Int Health. 2012;17(2):247-53.

41. Zeba MTA, Karou SD, Sagna T, Djigma F, Bisseye C, Ouermi D, et al. HCV prevalence and co-infection with HIV among pregnant women in Saint Camille Medical Centre, Ouagadougou. Trop Med Int Health. 2011;16(11):1392-6. https://doi.org/10.1111/j.1365-3156.2011.02845.x.

42. Kirakoya-Samadoulougou F, Sanou M, Samadoulougou S, Bakiono F, Kiénou K, Koumaré A, et al. High seroprevalence of hepatitis B virus and hepatitis $C$ virus among human immunodeficiency virus carriers in blood donors of Burkina Faso: a need for their screening before HARRT therapy. J Viral Hepat. 2014;21(7):e52-3.

43. Kania D, Bekalé AM, Nagot N, Mondain AM, Ottomani L, Meda N, et al. Combining rapid diagnostic tests and dried blood spot assays for point-of-care testing of human immunodeficiency virus, hepatitis B and hepatitis C infections in Burkina Faso, West Africa. Clin Microbiol Infect. 2013;19(12):12-8.

44. Zeba MTA, Sanou M, Bisseye C, Kiba A, Nagalo BM, Djigma FW, et al. Characterisation of hepatitis $C$ virus genotype among blood donors at the regional blood transfusion centre of Ouagadougou, Burkina Faso. Blood Transfus. 2014;12(SUPPL1):2-5.
45. Tao I, Bisseye C, Nagalo BM, Sanou M, Kiba A, Surat G, et al. Screening of hepatitis $G$ and epstein-barr viruses among voluntary non remunerated blood donors (VNRBD) in Burkina Faso, West Africa. Mediterr J Hematol Infect Dis. 2013;5(1):1-5.

46. Kissou SA, Koura M, Sawadogo A, Ouédraogo AS, Traoré H, Kamboulé $E$, et al. Étude des marqueurs sérologiques des hépatites virales $B$ et $C$ chez les drépanocytaires suivis en pédiatrie au CHU de Bobo-Dioulasso (Burkina Faso). Bull Soc Pathol Exot. 2017;110(3):160-4.

47. Yooda AP, Sawadogo S, Soubeiga ST, Obiri-Yeboah D, Nebie K, Ouattara AK, et al. Residual risk of HIV, HCV, and HBV transmission by blood transfusion between 2015 and 2017 at the regional blood transfusion center of Ouagadougou, Burkina Faso. J Blood Med. 2019;10:53-8.

48. Diarra B, Ouattara A, Djigma F, Compaore T, Obiri-Yeboah D, Traore L, et al. World hepatitis day in Burkina Faso, 2016: awareness, screening, identification of HBV markers, HBV/HCV coinfection, and vaccination. Hepat Mon. 2017;17(6):4-11.

49. Yooda AP, Soubeiga ST, Nebie KY, Diarra B, Sawadogo S, Ouattara AK, et al. Impact of multiplex PCR in reducing the risk of residual transfusiontransmitted. Mediterr J Hematol Infect Dis. 2018;10(1):1-9.

50. Tao I, Compaoré TR, Diarra B, Djigma F, Zohoncon TM, Assih M, et al. Seroepidemiology of Hepatitis B and C Viruses in the General Population of Burkina Faso. Hepat Res Treat. 2014;2014:1-5.

51. Simpore J, Granato M, Santarelli R, Nsme RAA, Coluzzi M, Pietra V, et al. Prevalence of infection by HHV-8, HIV, HCV and HBV among pregnant women in Burkina Faso [2]. J Clin Virol. 2004;31 (1):78-80.

52. Ouedraogo A, Kaboré M, Barry A, Coulibaly S, Ouattara D, Kargougou $D$, et al. Prevalence of HIV, hepatitis $B$ and hepatitis $C$ infection among potential participants to experimental vaccines trials in a rural area of Burkina Faso. Am J Trop Med Hyg. 2018;99(4 Suppl(345)):718.

53. Pietra V, Kiema D, Sorgho D, Kabore SCG, Mande S. Prevalence of hepatitis $B$ virus markers and hepatitis $C$ virus antibodies in health personnel in the District of Nanoro, Burkina Faso. Sci Tech. 2008;31:53-9.

54. Ekouevi DK, Coffie PA, Tchounga BK, Poda A, Jaquet A, Dabis F, et al. Prevalence of hepatitis $C$ among HIV-1, HIV-2 and dually reactive patients: a multi-country cross-sectional survey in West Africa. J Public Health Africa. 2018;9(2):100-4.

55. Sawadogo A, Kyelem CG, Yaméogo TM, Barro L, Kamboulé BE, Dahourou H. Statut du portage du virus de l'hépatite B (VHB) au sein du personnel de santé du CHU Sourô Sanou de Bobo-Dioulasso, Burkina Faso. J Afr d'Hépato-Gastroentérol. 2015;9(1):30-4. https://doi.org/10.1007/ s12157-014-0582-4.

56. Ouedraogo HG, Kouanda S, Grosso A, Compaoré R, Camara M, Dabire C, et al. Hepatitis B, C, and D virus and human T-cell leukemia virus types 1 and 2 infections and correlates among men who have sex with men in Ouagadougou, Burkina Faso. Virol J. 2018;15(1):194.

57. Ouedraogo HG, Kouanda S, Goodman S, Lanou HB, Ky-Zerbo O, Samadoulougou BC, et al. Hepatitis B, C and delta viruses'infections and correlate factors among female sex workers in Burkina Faso, West-Africa. Open Virol J. 2019;13(1):9-17.

58. Dah TTE, Couderc C, Coulibaly A, Kouamé MJ-B, Agboyibor MK, Traoré I, et al. Hepatitis $B$ virus prevalence and vaccination in men who have sex with men in West Africa (CohMSM ANRS 12324-Expertise France). Open Forum Infect Dis. 2019;6(7). /pmc/articles/PMC6602381/?report=abstract

\section{Publisher's Note}

Springer Nature remains neutral with regard to jurisdictional claims in published maps and institutional affiliations. 